\title{
Characteristics of Densified Oil Palm Empty Fruit Bunches Blended with Carbon Nanotube Particles
}

\author{
Nurulhuda A. Rahman ${ }^{1}$, Mohd Faizal Hasan ${ }^{1,2 *}$, Bemgba B. Nyakuma ${ }^{3}$, Mohd Rosdzimin Abdul Rahman ${ }^{4}$, Md. \\ Mizanur Rahman ${ }^{1}$, Shahrul A. Osman ${ }^{5}$, Mohamad Asrul Bosiran ${ }^{5}$, Tuan Amran T. Abdullah ${ }^{3}$ \\ ${ }^{1}$ School of Mechanical Engineering, Faculty of Engineering, Universiti Teknologi Malaysia, 81310 Johor Bahru, Johor, \\ Malaysia \\ ${ }^{2}$ Automotive Development Centre (ADC), Institute for Vehicle System and Engineering, Universiti Teknologi Malaysia, \\ 81310 Johor Bahru, Johor, Malaysia \\ ${ }^{3}$ School of Chemical and Energy Engineering, Faculty of Engineering, Universiti Teknologi Malaysia, 81310 Johor Bahru, \\ Johor, Malaysia \\ ${ }^{4}$ Department of Mechanical Engineering, Faculty of Engineering, Universiti Pertahanan Nasional Malaysia, Kem Sg. Besi, \\ 57000, Kuala Lumpur, Malaysia \\ ${ }^{5}$ Faculty of Mechanical and Manufacturing Engineering, Universiti Tun Hussein Onn Malaysia, 86400 Parit Raja, Johor, \\ Malaysia
}

Corresponding Author Email: mfaizal@mail.fkm.utm.my

https://doi.org/10.18280/acsm.440102

Received: 16 October 2019

Accepted: 8 December 2019

\section{Keywords:}

EFB, palm biomass, densification, empty fruit bunch, CNT, briquettes, palm oil

\begin{abstract}
In the present study, the mechanical (bulk), physicochemical, and thermal properties of densified empty fruit bunch (EFB) and carbon nanotube (CNT) were examined at various mixing ratios. A press machine initially produced the EFB briquettes with an operating pressure of $7 \mathrm{MPa}$ and briquetting temperature of $150^{\circ} \mathrm{C}$ for 30 minutes. The results show that an increase in weight fraction of CNT causes a significant increase in gross calorific value (from $17900 \mathrm{~kJ} / \mathrm{kg}$ to $19200 \mathrm{~kJ} / \mathrm{kg}$ ) and fixed carbon content (from $18 \%$ to $28 \%$ ). However, the reduction in relaxed density (from $1300 \mathrm{~kg} / \mathrm{m}^{3}$ to $1100 \mathrm{~kg} / \mathrm{m}^{3}$ ), moisture ( $8 \%$ to $7.5 \%$ ), volatile matter (62\% to $70 \%$ ), and ash (from $3.9 \%$ to $3.1 \%$ ) was recorded. Furthermore, the gross calorific value and fixed carbon content were improved with the addition of CNT to EFB. However, the thermal analysis revealed that CNT addition marginally affected the thermal degradation behaviour and temperature profile characteristics of the briquettes. In conclusion, the relaxed density, gross calorific value and moisture of the EFB-CNT briquettes fulfilled the requirement for commercialisation as stated by international benchmarks. The findings of the present study reveal the potential of EFB briquettes blended with CNT particles to become as a source for future energy.
\end{abstract}

\section{INTRODUCTION}

Currently, fossil fuels comprising oil, natural gas and coal are the most critical energy resources, accounting for $86 \%$ of global primary energy [1]. Due to growing concerns about global warming and climate changes, alternative sources of energy are urgently needed to safeguard the environment. Theoretically, the renewable energy sources such as wind, solar, geothermal and marine resources could provide the total energy consumed per day worldwide [2]. Currently, Malaysia contributes $39 \%$ of world palm oil production and $44 \%$ of global exports [3]. As one of the largest producers and exporters of palm oil products, Malaysia has a cheap and widely available source of oil palm biomass, which could be potentially converted into renewable and sustainable energy and fuels. Typically, the palm oil mills generate over 30 million tonnes of major oil palm biomass wastes [4], comprising empty fruit bunch (EFB), mesocarp fibre (MSF), and kernel shell (PKS) annually [5, 6]. Therefore, there is an enormous potential for transforming these abundant wastes especially EFB into a renewable fuel for electricity generation at steam power plants in Malaysia.

Carbon nanotubes (CNT) are unique nanostructured materials commonly utilised for various applications in science, technology and industry. For example, CNT is considered ideal materials for reinforcing fibres due to their exceptional mechanical, thermal, and electrical properties [7, 8]. The strength of CNT has been experimentally and theoretically proven due to its carbon bonds. Moreover, CNTs are extremely promising raw materials for the development of high-performance nanostructured materials due to their low density [9]. The utilisation of CNT in natural fibre reinforced composite improves the mechanical properties with epoxy matrix $[10,11]$.

Several researchers have also utilised CNT for applications in the synthesis of various fuels $[12,13]$ and other value-added products $[14,15]$. The addition of CNT can enhance combustion characteristics [16]. Furthermore, Moy et al., [17] reported that the addition of CNT (wt.\% of CNT=1-15\%) enhanced the burning rate of liquid fuels in a spark ignition (SI) engines. Besides, the study demonstrated that CNT addition enhanced the anti-knock properties of the engine [17]. 
In another study, Alias et al. [18] examined the effect of CNT dispersions on the properties of palm oil biodiesel blends. The authors observed that CNT improved the fuel properties particularly thermal conductivity and flash point. When the volume percentage of CNT added was increased to $2.5 \%$, the thermal conductivity improved from $6 \%$ to $10 \%$ [18].

Furthermore, several authors have demonstrated that CNT blended water-diesel emulsion fuels can enhance engine thermal efficiency and reduce pollutants $[13,14,16]$. Basha et al. [13] found that at the full load, carbon nanotubes (CNT) and Di-Ethyl Ether (DEE) blended biodiesel emulsion fuels give brake thermal efficiency, $\mathrm{NO}$ and smoke emission of $28.8 \%, 895 \mathrm{ppm}$ and $36 \%$, respectively, while pure diesel gives $25.2 \%, 1340 \mathrm{ppm}$ and $71 \%$, respectively. Therefore, it can be asserted that the addition of CNT improves the combustion properties of liquid fuels such as diesel. However, research studies on the effects of CNT on the performance of solid fuels (e.g. palm biomass) remain lacking. Therefore, this study presents a novel approach to utilise pulverised EFB blended with CNT as a potential fuel for enhanced energy recovery. In addition, the study seeks to examine and understand the characteristics of densified EFB blended with $\mathrm{CNT}$ in various ratios.

Densification is a practical technique used to improve the fuel properties, transportation, and handling of solid fuels [19]. It involves compacting loose biomass materials under pressure into solid compact fuel with higher density [20, 21]. The technique has several advantages such as increased energy and volumetric density, reduced dust formation along with improvement in moisture content and burning rate [22, 23]. In the present study, the bulk mechanical properties (relaxed density and durability), physicochemical properties (moisture, ash, volatile matter, fixed carbon, and gross calorific value) and thermal properties (combustion) of densified EFB with CNT blends were comprehensively examined. Next, the properties of the densified products were compared with the requirements for commercialization as stated by DIN 51731 and several ISO standards.

The following chapters are organized as follows: Section 2 describes about preparation of raw materials, procedures for densification and important analysis. The following Section 3 elaborates the discussion for the results obtained from the experiment while the final section (Section 4) presents the conclusion of the present study.

\section{MATERIAL AND METHODS}

\subsection{Raw materials and sample preparation}

Table 1. Basic properties of CNT

\begin{tabular}{cc}
\hline Parameter & Properties \\
\hline Outer diameter & $20-30 \mathrm{~nm}$ \\
Length & $10-30 \mu \mathrm{m}$ \\
Purity & $95 \%$ \\
Odour & Odourless \\
Melting range & $3652-3697^{\circ} \mathrm{C}$ \\
Density & $2.1 \mathrm{~g} / \mathrm{cm}^{3}$ \\
\hline
\end{tabular}

In this study, pulverised empty fruit bunch (EFB) and CNT were used as raw materials. The shredded EFB fibres were obtained from a near palm oil mill before being dried and ground into powder. Next, the ground EFB fibres were sieved to obtain the desired homogenous particles with a diameter below $500 \mu \mathrm{m}$. Meanwhile, the CNT was supplied by Chengdu Organic Chemical (Chinese Academy of Science, China) in the commercial single walled form. The basic properties of the CNT are presented in Table 1.

\subsection{Briquetting process}

The mixture of EFB and CNT for briquetting was prepared in the weight ratio of 95:5, 90:10, and 85:15. The mixture was subsequently rotated at a speed of 160-165 rpm for 2 hours using a lab roller mixer to obtain a homogenous composition. The weight of each sample was approximately 40 grams. Subsequently, the briquettes were prepared with different EFB to CNT weight ratios of $95: 5,90: 10$ and $85: 15$. The experimental setup for briquetting is shown by Figure 1. The compaction process involved placing the samples inside the die set (comprising the base, wall and piston). Next, the piston was pushed slowly into the die set until it reached the sample. The samples and the die set were placed between two plates of the piston press machine (Tehcnopress $100 \mathrm{HC}-\beta$ ).

The EFB and CNT mixtures were subsequently compressed by the press machine (with a hydraulic piston diameter of 120 $\mathrm{mm}$ ) at the desired pressure of $7 \mathrm{MPa}$ and temperature of $150^{\circ} \mathrm{C}$ for the residence time of 30 minutes. Finally, the produced briquettes were placed under ambient condition approximately for a week to obtain stability and rigidity. In the present study, three briquettes were produced for each weight ratio of $95: 5,90: 10$ and $85: 15$.

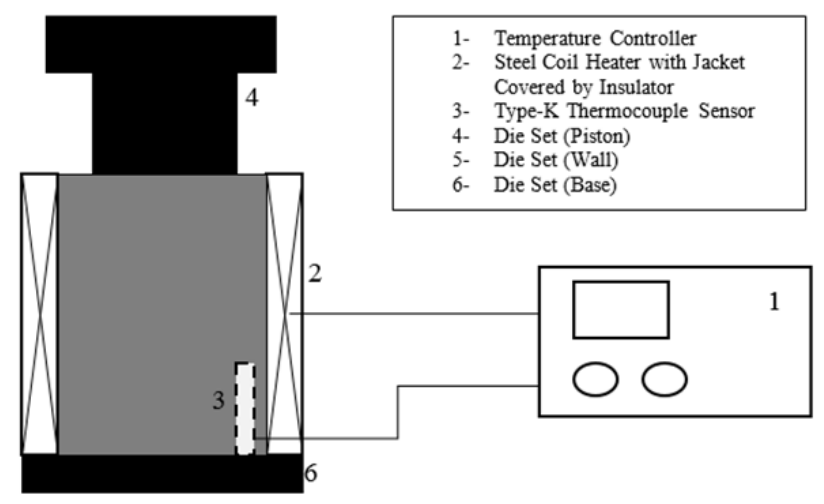

Figure 1. Experimental setup for briquetting

\subsection{Bulk mechanical analysis}

The bulk or mechanical properties of the briquettes comprising the relaxed density and mechanical durability were examined as highlighted in the procedures in sections 2.3.1 and 2.3.2.

\subsubsection{Relaxed density}

The relaxed density was determined using the geometric formulae, which measures the volume and mass of the briquettes [24]. The measurement of the volume and mass was performed using a calliper gauge and a precise mechanical balance (Model: FX-300i), respectively.

\subsubsection{Mechanical durability}

The mechanical durability of the briquettes was determined by performing the drop test $[25,26]$. Hence, the briquettes were dropped from a height of $1.85 \mathrm{~m}$ onto a flat steel plate. This procedure was repeated four times for each briquette to 
investigate the reliability of the briquettes produced. Next, the weight of the briquette was measured after each drop whereas the durability was calculated based on Eq. (1).

$$
\begin{aligned}
& \text { Durability (\%) } \\
& =\frac{\text { Final Weight of Briquette after four drops }}{\text { Initial Weight of Briquette }} \\
& \times 100
\end{aligned}
$$

\subsection{Physicochemical analysis}

The physicochemical properties of EFB, CNT and the blend mixtures were examined by ultimate (elemental), proximate, and gross calorific (higher heating) value. The procedures, standard codes and procedures adopted are presented in the next sections.

\subsubsection{Ultimate analysis}

The ultimate analysis of the sample was performed using the CHNS elemental analyser (Model: vario MICRO CUBE, Germany), according to standards BS EN ISO 16948:2015 for the determination of carbon, hydrogen, nitrogen, and sulphur contents. Lastly, the oxygen contents were determined by difference.

\subsubsection{Proximate analysis}

Proximate analysis was carried out according to the American Society for Testing and Materials standards (ASTM D3173-D3175) for the determination of the moisture, ash and volatile matter. However, the content of fixed carbon was obtained by deducting the summation of moisture, volatile matter and ash contents from $100 \%$.

\subsubsection{Gross calorific value}

The determination of gross calorific value was performed by using a bomb calorimeter system (Model: IKA C2000 calorimeter system) for all briquettes produced along with the raw materials of EFB and CNT based on the ASTM standard D240.

\subsection{Thermal analysis}

The thermal analysis of the samples was examined by thermogravimetric analysis (TGA) to examine the oxidative, thermal degradation behaviour, and the characteristic temperature profiles of the EFB, CNT and the EFB/CNT blends 95:5, 90:10 and 85:15.

\subsubsection{Thermogravimetric analysis (TGA)}

The thermogravimetric analysis (TGA) was carried out under non-isothermal oxidative conditions to simulate the combustion of the EFB, CNT and the EFB/CNT blends 95:5, 90:10 and 85:15 samples. For each test, approximately 6-10 $\mathrm{mg}$ of each sample was placed in alumina crucible before transferring to the furnace of the TG Analyser (Model: Shimadzu TG-50, Japan). Next, the sample was heated from $30^{\circ} \mathrm{C}$ to $900^{\circ} \mathrm{C}$ based on the non-isothermal heating rate of $20{ }^{\circ} \mathrm{C} / \mathrm{min}$ under air flow rate $(20 \mathrm{~mL} / \mathrm{min})$ to simulate combustion of the samples. On completion, the TGA was cooled to room temperature whereas the raw TGA data was recovered and analysed through the Shimadzu Thermal analysis software (Version: Workstation TA-60WS). Subsequently, the mass loss (TG, \%), and derivative mass loss (DTG, \%/min) was plotted against temperature to examine the oxidative degradation of the samples.

\subsubsection{Temperature profile characteristics (TPC)}

Based on the TG-DTG plots, the temperature profile characteristics (TPC) comprising; ignition $\left(T_{\text {ons }}\right)$, midpoint $\left(T_{m i d}\right)$, maximum decomposition $\left(T_{\max }\right)$, and burnout $\left(T_{\text {off }}\right)$ temperatures, as well as the mass loss (ML, \%) and residual mass (RM, \%) of the samples, were examined. The TPC values were determined using the tangent method [27], which is embedded in the Shimadzu Thermal analysis software (Version: Workstation TA-60WS). The $T_{\text {ons }}$ (onset or ignition) is defined as the temperature in which a material begins to undergo thermal degradation during TGA. The midpoint $\left(T_{\text {mid }}\right)$ is the halfway or middle temperature of the TG plot, whereas the burnout $\left(T_{\text {off }}\right)$ temperature is the final temperature of devolatilization during TGA. However, the $T_{\max }$ or maximum decomposition temperature is determined from the DTG plots and denotes the temperature in which the highest thermal degradation of the sample occurs during TGA. Lastly, the mass loss $\left(\mathrm{M}_{\mathrm{L}}, \%\right)$ represent the total loss of mass of the sample, whereas the residual mass $\left(\mathrm{R}_{\mathrm{M}}, \%\right)$ denotes mass of the residues resulting after thermal degradation [27, 28].

\section{RESULTS AND DISCUSSION}

\subsection{Briquette morphology}

The characterisation of the briquettes produced revealed a distinct physical appearance. Figure 2 shows the physical appearance of briquettes with various mixing ratios of EFB and CNT.
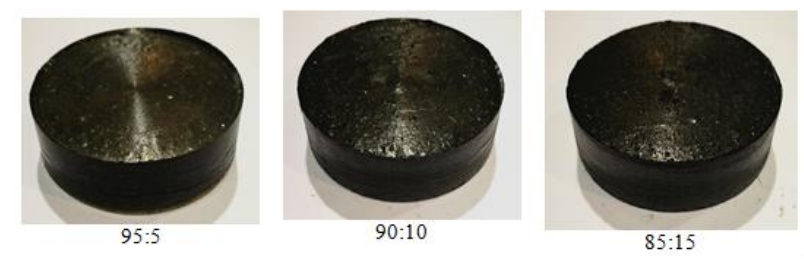

Figure 2. Briquettes at different mix ratios (EFB: CNT)

As observed, the densification process resulted in round solid uniform shaped briquettes regardless of the mixing ratio. Furthermore, the mixture of EFB and CNT turned into dark brown after the briquetting process. This is due to the presence of CNT during the biomass sweating which contributes to this phenomenon. Next, the EFB and CNT briquettes were characterised to examine its mechanical (bulk), physicochemical, calorific, and thermal properties.

\subsection{Bulk physical properties}

The results of the bulk physical properties of the EFB and CNT briquettes comprising the relaxed density and mechanical durability are presented in this section of the paper.

\subsubsection{Relaxed density}

The density is an important characteristic that describes the energy content per unit volume of the briquettes produced. As shown in Figure 3, the addition of 5 wt.\% of CNT increased the briquette density by $13 \%$ compared to briquettes made of $100 \%$ pulverised EFB. The increment is attributed to the infiltration of CNTs into the pulverised EFB matrix. In this 
case, the current high lignin content still dominates the formation of briquettes, thereby resulting in the production of briquettes with sufficiently small volume.

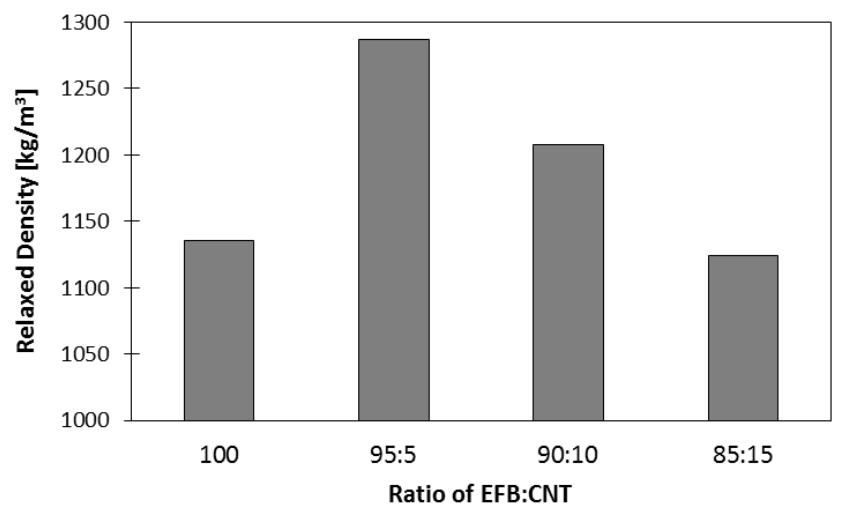

Figure 3. Briquettes at different mixing ratios (EFB: CNT)

Conversely, the increase in the weight percentage of CNT reduced the relaxed density (RD) of the briquettes. The decline in $\mathrm{RD}$ is due to the appearance of cracks as the regions involved with binding mechanism starts to diminish due to substitution by CNT. Besides, the increase in CNT fraction created a larger volume of pores in the briquettes. As a result, the density of the briquettes decreased with increasing CNT ratio [29]. Based on density standard (1000 to $\left.1400 \mathrm{~kg} / \mathrm{m}^{3}\right)$ of DIN 51731, it was found that the briquettes fulfil the requirement for the commercialisation of densified fuels.

\subsubsection{Mechanical durability}

Although the addition of CNT in the briquettes lowered the relaxed density, an opposite trend was observed for mechanical durability. According to the EN ISO 17831-2 standard for commercial densified fuels, the mechanical durability should be higher than $90 \%$. Figure 4 presents the results of the effect of CNT addition on the mechanical durability of briquettes at various mixing ratios.

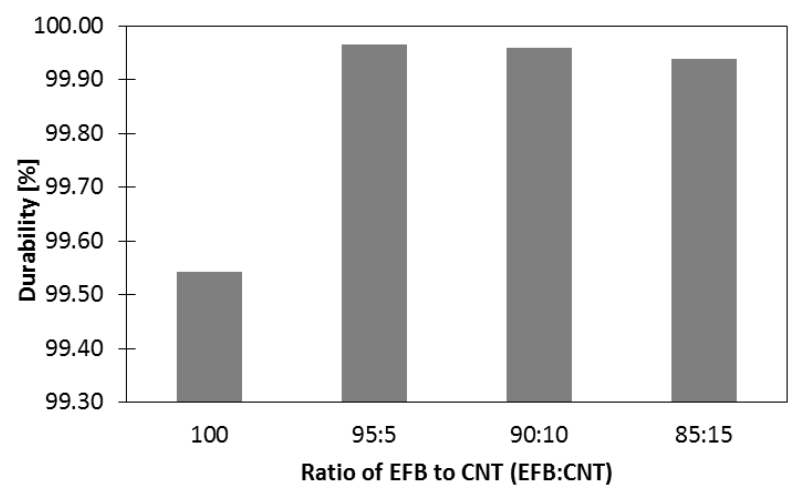

Figure 4. Durability of briquettes at various mixing ratios

As observed, the briquettes showed highly durability above 99\%, which indicates the addition of CNT improved the durability. Furthermore, the results indicate that the produced briquettes are physically durable. This is because lignin content in the EFB binds or bridges the CNT and EFB particles, thus producing highly durable briquettes. Lastly, the results suggest that durability is not affected by the cracked surface produced during the densification process.

\subsection{Physicochemical properties}

\subsubsection{Ultimate, proximate, and calorific analyses}

The ultimate and proximate analysis of the pulverised oil palm empty fruit bunches (EFB) and carbon nanotubes (CNT) raw materials are presented in Table 2 . The results show that EFB and CNT both have low moisture content $(<10 \%)$, which fulfil the requirement for commercial fuel stated in DIN51731 and EN 14774-3 standard test methods. However, the ash content of both materials is higher than the minimum requirement of $0.7 \%$ as stated in the DIN5173 standard. Besides, there is a significant difference in the volatile matter between the pulverised EFB and CNT. As observed, the CNT is almost pure carbon (98 wt.\%) with a significantly high fixed carbon (81.3 wt.\%) compared to EFB.

Table 2. Physicochemical properties of EFB/CNT raw materials

\begin{tabular}{|c|c|c|c|c|}
\hline Analysis & $\begin{array}{l}\text { Element/ } \\
\text { property }\end{array}$ & $\begin{array}{c}\begin{array}{c}\text { Symbol } \\
\text { (Unit) }\end{array} \\
\end{array}$ & EFB & CNT \\
\hline \multirow{5}{*}{ Ultimate } & Carbon & $\mathrm{C}$ (wt.\%) & 41.17 & 98.00 \\
\hline & Hydrogen & H (wt.\%) & 7.43 & 0.14 \\
\hline & Nitrogen & $\mathrm{N}$ (wt.\%) & 0.84 & 0.16 \\
\hline & Sulphur & S (wt.\%) & 0.15 & 0.08 \\
\hline & Oxygen & $\mathrm{O}$ (wt.\%) & 50.42 & 1.62 \\
\hline \multirow{4}{*}{ Proximate } & Moisture & MC (wt.\%) & 7.02 & 0.87 \\
\hline & Volatile & VM (wt.\%) & 75.54 & 16.20 \\
\hline & Fixed carbon & FC (wt.\%) & 13.94 & 81.26 \\
\hline & Ash content & $\mathrm{A}(\mathrm{wt} . \%)$ & 3.51 & 1.67 \\
\hline Calorific & $\begin{array}{c}\text { Gross Calorific } \\
\text { Value }\end{array}$ & $\begin{array}{c}\mathrm{GCV} \\
(\mathrm{MJ} / \mathrm{kg})\end{array}$ & 16.94 & 31.90 \\
\hline
\end{tabular}

Next, the physicochemical analysis of the EFB/CNT mixing ratios was examined, as presented in Table 3. As observed, the percentage composition of carbon increased whereas the hydrogen content decreased with the addition of CNT in the briquette mixture. This is mainly due to the significantly high carbon content but low hydrogen content of the raw CNT, as shown in Table 3. Lastly, the percentage composition of oxygen also clearly decreased with the increase in CNT content in the mixture.

The gross calorific value (GCV) of empty fruit bunch (EFB) and carbon nanotubes (CNT) was also examined as presented in Table 2. As observed, gross calorific value for EFB is 16.94 $\mathrm{MJ} / \mathrm{kg}$, which does not differ markedly from values (17.02 $\mathrm{MJ} / \mathrm{kg}-18.88 \mathrm{MJ} / \mathrm{kg}$ ) reported in the previous research works [30-32]. The observed differences are ascribed to the various pre-treatment, biological, and physicochemical, factors such as moisture content, age, time of harvesting of the EFB, which influence the lower gross calorific value $[21,33]$.

In comparison, GCV of EFB is slightly lower than the minimum requirement $(17500 \mathrm{~kJ} / \mathrm{kg}$ ) for commercial densified fuels based on the DIN 51731 standard. Meanwhile, CNT has sufficiently high gross calorific value. Therefore, the addition of CNT to pulverised EFB during the briquetting will enhance the combustion properties to meet the standard requirements for commercialisation.

The proximate analysis of briquettes with different mixing ratios of EFB and CNT are presented in Figure 5. The results revealed that $\mathrm{EFB} / \mathrm{CNT}$ briquettes have higher moisture content (7.53-8.42 wt.\%) compared to the raw materials $(\mathrm{EFB}=7.02 \mathrm{wt} . \% ; \mathrm{CNT}=0.87 \mathrm{wt} . \%)$. This is supposedly due to the modification of the mixture properties after simultaneous heating and briquetting. The similar situation also has been 
observed in the previous study [34]. The moisture content of briquettes depends on that of the raw material, although the values reportedly change during the briquetting process [35]. The authors observed that a fraction of the raw material moisture content evaporates when the temperature increases during compression.

Table 3. Results of ultimate analysis

\begin{tabular}{ccccc}
\hline \multirow{2}{*}{ Element/Property } & \multirow{2}{*}{ Symbol (unit) } & \multicolumn{3}{c}{ Mix ratio (EFB: CNT) } \\
& & $\mathbf{9 5 : 0 5}$ & $\mathbf{9 0 : 1 0}$ & $\mathbf{8 5 : 1 5}$ \\
\hline Carbon & C (wt.\%) & 44.88 & 46.88 & 49.75 \\
Hydrogen & H (wt.\%) & 6.35 & 6.07 & 5.79 \\
Nitrogen & N (wt.\%) & 0.75 & 0.82 & 0.73 \\
Sulphur & S (wt.\%) & 0.14 & 0.16 & 0.13 \\
Oxygen & O (wt.\%) & 47.88 & 46.08 & 43.60 \\
\hline
\end{tabular}

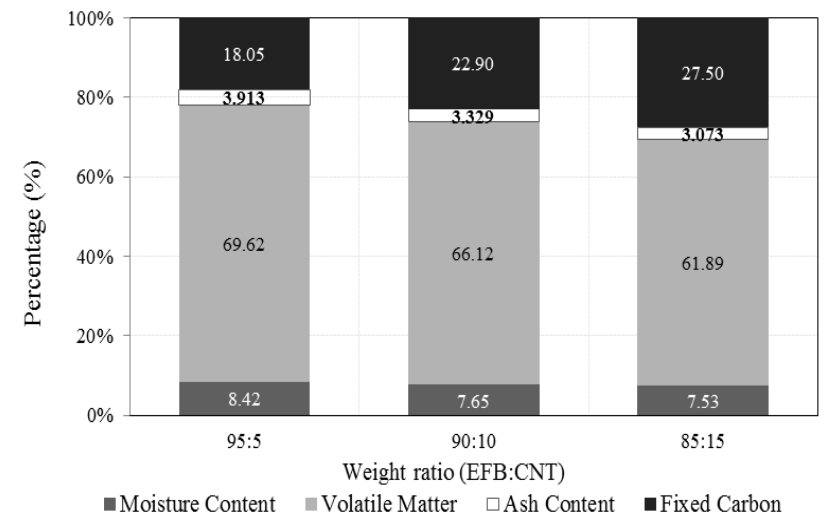

Figure 5. Proximate analysis for briquettes with various mixing ratios

As observed in Figure 5, when the weight fraction of CNT was increased from $5 \%$ to $15 \%$, the moisture content decreased from $8.4 \%$ and $7.5 \%$, respectively. The decreasing trend was due to the low moisture content $(0.87 \%)$ of CNT. As a result, the moisture content of the briquettes produced fulfilled the requirement for commercial purposes, as stated by DIN 51731 and based on EN 14774-3 testing standard $(<10 \%)$.

Similarly, the increase in the weight fraction of CNT from $5 \%$ to $15 \%$, resulted in a decrease in volatile matter content from $69.6 \%$ to $61.9 \%$, whereas the fixed carbon increased from $18.1 \%$ to $27.5 \%$. This reveals that the high fixed carbon content of CNT contributes to the increase in fixed carbon content and the decrease in the volatile matter. Lastly, the ash content also decreased from $3.9 \%$ to $3.1 \%$ when the mix ratio of CNT was increased from $5 \%$ to $15 \%$. The decrease in ash is mainly because of the low ash content $(\sim 1.7 \%)$ of CNT raw material. Overall, it can be concluded that the addition of CNT strongly influenced the fuel properties of the EFB/CNT briquettes.

The gross calorific value (GCV) analysis of the EFB/CNT briquettes was also examined in this study as presented in Figure 6. As observed, the GCV of briquettes increased with the increase in CNT weight fraction from $5 \%$ to $15 \%$. This indicates that the addition of CNT resulted in a $5.7 \%$ to $13.3 \%$ increase in the GCV of the EFB/CNT briquettes.

The results demonstrate that the addition of CNT enhances the GCV of the briquettes. This observation confirms the interrelationship between GCV and the percentage of carbon composition in the briquettes. Lastly, the results indicate that the GCV of the EFB/CNT briquettes fulfils the minimum calorific requirements of $17500 \mathrm{~J} / \mathrm{g}$ for commercialisation, based on DIN 51731 standard.

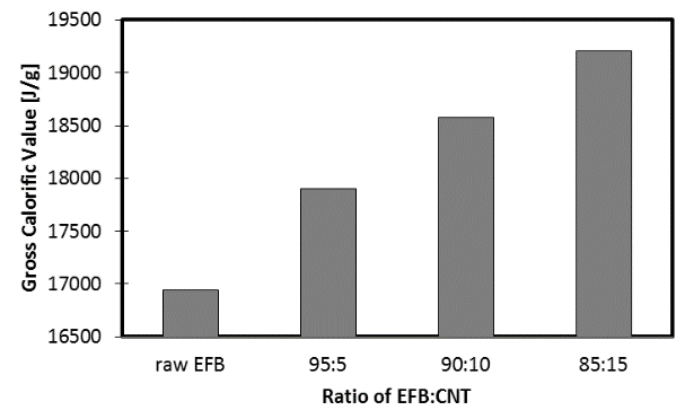

Figure 6. Gross calorific value (GCV) of briquettes with various mixing ratios

\subsection{Thermal properties}

The thermal properties of the raw materials (EFB and CNT) along with the briquettes were examined by thermogravimetric analysis (TGA). The findings present insights into the thermal properties of the raw materials and the briquettes with various mixing ratios.

\subsubsection{Thermogravimetric (TGA) analysis}

The TG plots for the raw material (EFB and CNT) along with the EFB/CNT blends 95:5, 90:10 and 85:15 are presented in Figure 7. The samples were heated from $30^{\circ} \mathrm{C}$ to $900^{\circ} \mathrm{C}$ at a heating rate of $20^{\circ} \mathrm{C} / \mathrm{min}$ under an air flow rate of $20 \mathrm{~mL} / \mathrm{min}$ to examine the combustibility, thermal degradation behaviour, and temperature profiles of the samples.

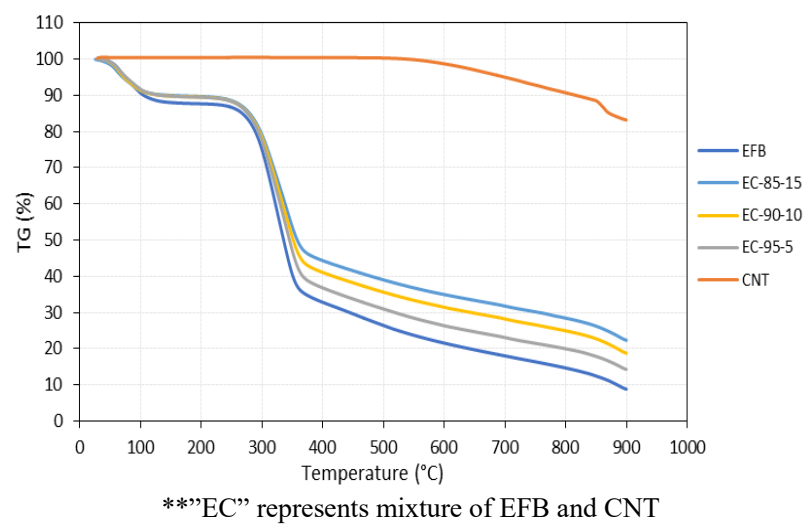

Figure 7. TG plots for EFB, CNT and briquettes with various mixing ratios $(95: 5,90: 10$ and $85: 15)$

As observed, TG plots for the EFB and the mixing blends 95:5, 90:10 and 85:15 display the typical downward " $Z$ " trend as observed for thermally decomposing materials reported in the literature [28]. This trend typically indicates that the material is undergoing stepwise thermal decomposition due to drying, devolatilization, and char degradation [36, 37] which results in a significant mass loss during TGA. As observed, the increase in the CNT fraction in the blends caused the TG plots to shift to the right-hand side of the plots or higher temperatures. This indicates that the addition of CNT increases the thermal stability or resistance to thermal decomposition of the briquettes. This is ascribed to the higher carbon, and fixed carbon of the CNT, which lowers the thermal decomposition or reactivity of the blends, as similarly reported for high ranked coals and petroleum coke [38, 39]. 
The DTG plots for the raw materials (EFB and CNT) as well as for the briquettes with various EFB/CNT blends of 95:5, 90:10 and 85:15 are presented in Figure 8.

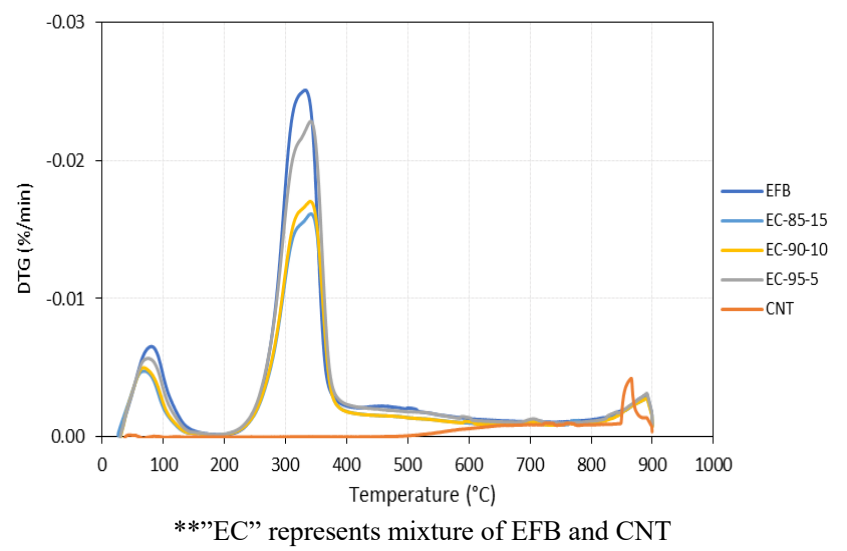

Figure 8. DTG plots for EFB, CNT and mix blends (95:5, 90:10 and 85:15)

As observed, the thermal degradation of the samples resulted in three sets of endothermic peaks in the temperature ranges; (a) $30^{\circ} \mathrm{C}$ to $200^{\circ} \mathrm{C}$, (b) $200^{\circ} \mathrm{C}$ to $400^{\circ} \mathrm{C}$, and lastly, (c) $850^{\circ} \mathrm{C}$ to $900^{\circ} \mathrm{C}$. This indicates that the thermal degradation of the samples occurred in four (4) stages as clearly evident in Figure 8 . The first stage from $30^{\circ} \mathrm{C}$ to $200^{\circ} \mathrm{C}$ is typically attributed to the loss of moisture and low molecular weight volatile matter [40]. The second stage from $200^{\circ} \mathrm{C}$ to $400^{\circ} \mathrm{C}$ is ascribed to the loss of volatile matter (devolatilization) from the samples [36, 37]. As a result, the loss of mass from the samples during this stage is significant as typified by the large size, shape and symmetry of the peak in Figure 8 . Stage three which occurs from $400^{\circ} \mathrm{C}$ to $850^{\circ} \mathrm{C}$ is characterised by the slow degradation of the char formed during the devolatilization process in stage two. Lastly, stage four occurred from $850^{\circ} \mathrm{C}$ to $900^{\circ} \mathrm{C}$ is due to the char oxidation or degradation. Overall, the results along with the shape, size and symmetry of the DTG plots and peaks indicate that the degradation mechanism of $\mathrm{EFB}, \mathrm{CNT}$ and the briquettes is similar and hence undergoing synergic interaction as earlier reported. Next, the temperature profiles of the samples were examined to deduce the thermal degradation behaviour.

\subsubsection{Temperature Profile Characteristics (TPC)}

Based on the TG-DTG plots, the temperature profile characteristics (TPC) for the raw materials (EFB and CNT) along with the EFB/CNT blends 95:5, 90:10 and 85:15 were examined. The TPCs examined in this study include; ignition $\left(T_{\text {ons }}\right)$, midpoint $\left(T_{\text {mid }}\right)$, maximum decomposition $\left(T_{\max }\right)$, and burnout $\left(T_{\text {off }}\right)$ temperatures, as well as the mass loss (ML, \%) and residual mass (RM, \%) of the samples, as presented in Table 4.

As observed, the ignition $\left(T_{\text {ons }}\right)$, midpoint $\left(T_{m i d}\right)$, maximum decomposition $\left(T_{\max }\right)$, and burnout $\left(T_{\text {off }}\right)$ temperatures of EFB are significantly lower than CNT. This is due to the lignocellulosic nature of EFB which enhanced its thermal reactivity compared to the highly inorganic nature of CNT comprising high carbon and fixed carbon. As a result, the EFB was significantly degraded during TGA as evidenced by its higher mass loss $\left(\mathrm{M}_{\mathrm{L}}=91.5 \%\right)$ and lower residual mass $\left(\mathrm{R}_{\mathrm{M}}=8.6 \%\right)$ compared to the $\mathrm{M}_{\mathrm{L}}=17 \%$ and $\mathrm{R}_{\mathrm{M}}=83 \%$ for $\mathrm{CNT}$.

In comparison, the EFB/CNT briquette blends 95:5, 90:10 and $85: 15$ experienced thermal degradation patterns similar to EFB. As observed, the TPCs for the blends did not differ markedly from the EFB, which indicates that the addition of CNT did not significantly influence the thermal properties of the briquettes. This observation is to be expected, as the CNT was unreactive (Figure 7) during thermal degradation and hence will have a marginal impact on the reactivity based on the mass loss $\left(\mathrm{M}_{\mathrm{L}}, \%\right)$ and residual mass $\left(\mathrm{R}_{\mathrm{M}}, \%\right)$, despite improving the calorific values as earlier reported.

Table 4. TPCs for raw EFB, CNT and briquettes

\begin{tabular}{ccccccc}
\hline Sample & $\boldsymbol{T}_{\text {ons }}\left({ }^{\circ} \mathbf{C}\right)$ & $\boldsymbol{T}_{\boldsymbol{m i d}}\left({ }^{\circ} \mathbf{C}\right)$ & $\boldsymbol{T}_{\boldsymbol{m a x}}\left({ }^{\circ} \mathbf{C}\right)$ & $\boldsymbol{T}_{\text {off }}\left({ }^{\circ} \mathbf{C}\right)$ & $\mathbf{M}_{\mathbf{L}}(\mathbf{\%})$ & $\mathbf{R}_{\mathbf{M}}(\mathbf{\%})$ \\
\hline EFB & 266.27 & 319.99 & 333.06 & 372.71 & 91.45 & 8.56 \\
CNT & 756.91 & 770.74 & 865.44 & 876.84 & 16.97 & 83.03 \\
$\mathbf{8 5 - 1 5}$ & 265.60 & 322.41 & 341.66 & 380.31 & 77.61 & 22.39 \\
$\mathbf{9 0 - 1 0}$ & 265.53 & 322.41 & 339.87 & 378.96 & 81.43 & 18.57 \\
$\mathbf{9 5 - 5}$ & 269.65 & 323.29 & 341.36 & 380.45 & 85.78 & 14.22 \\
\hline
\end{tabular}

\section{CONCLUSION}

The briquettes made of pulverised empty fruit bunch and carbon nanotube particles have been successfully produced with various mixing ratios. It was found that the relaxed density, gross calorific value, and moisture content of the briquettes produced in the present study fulfil the minimum requirement for commercial purpose as stated by DIN 51731 and ISO standards. In terms of physical characteristics, it can be concluded that the briquettes produced were highly durable, with the durability of around $99 \%$, based on standard EN ISO 17831-2. Furthermore, the thermal properties revealed the CNT marginal effect on the thermal degradation behaviour and characteristics profiles of the $\mathrm{EFB} / \mathrm{CNT}$ briquettes produced. As an overall conclusion, the briquettes made of a mixture of pulverised EFB and CNT particles have high potential to be an alternative energy source to substitute the non-renewable energy sources as most of the critical criteria has been found to fulfil the minimum requirement for commercialisation. For future works, it is strongly recommended that the EFB briquettes blended with CNT particles to be pre-treated with torrefaction process for various temperatures for further improvement in terms of the combustion properties such as reduction in moisture content and increase in gross calorific value.

\section{ACKNOWLEDGMENT}

The authors wish to thank the Ministry of Higher Education Malaysia and Universiti Teknologi Malaysia for financial support through Tier 2 Grant (Vot No.: Q.J130000.2651.16J28). 


\section{REFERENCES}

[1] Saidur, R., Abdelaziz, E.A., Demirbas, A., Hossain, M.S., Mekhilef, S. (2011). A review on biomass as a fuel for boilers. Renewable and Sustainable Energy Reviews, 15(5):

$2262-2289$ https://doi.org/10.1016/j.rser.2011.02.015

[2] Nelder, C. (2019). The End of Fossil Fuel. https://bit.ly/2E5RSIm, accessed on Feb. 12, 2019.

[3] Alam, A., Er, A.C., Begum, H. (2015). Malaysian oil palm industry: Prospect and problem. Journal of Food, Agriculture \& Environment, 13(2): 143-148.

[4] Abdullah, N., Sulaiman, F. (2013). The oil palm wastes in Malaysia. Biomass Now-Sustainable Growth and Use, 1(3): 75-93. http://dx.doi.org/10.5772/55302

[5] Sing, C.Y., Aris, M.S. (2013). A study of biomass fuel briquettes from oil palm mill residues. Asian Journal of Scientific Research, 6(3): 537-545. http://dx.doi.org/10.3923/ajsr.2013.537.545

[6] Sukiran, M.A., Abnisa, F., Daud, W., Abu Bakar, N., Loh, S.K. (2017). A review of torrefaction of oil palm solid wastes for biofuel production. Energy Conversion and Management 149: $101-120$ https://doi.org/10.1016/j.enconman.2017.07.011

[7] Zhou, Y., Wu, P., Cheng, Z., Ingram, J., Jeelani, S. (2008). Improvement in electrical, thermal and mechanical properties of epoxy by filling carbon nanotube. Express Polymer Letters, 2(1): 40-48. http://dx.doi.org/10.3144/expresspolymlett.2008.6

[8] Díez-Pascual, A.M., Ashrafi, B., Naffakh, M., GonzálezDomínguez, J.M., Johnston, A., Simard, B., Martinez, M.T., Gómez-Fatou, M.A. (2011). Influence of carbon nanotubes on the thermal, electrical and mechanical properties of poly (ether ether ketone)/glass fiber laminates. Carbon, 49(8): 2817-2833. https://doi.org/10.1016/j.carbon.2011.03.011

[9] Verdejo, R., Lopez-Manchado, M., Valentini, L., Kenny, J. (2010). Carbon nanotube reinforced rubber composites. Rubber Nanocomposites, Wiley, Singapore, 147-168.

[10] Shen, X., Jia, J., Chen, C., Li, Y., Kim, J.K. (2014). Enhancement of mechanical properties of natural fiber composites via carbon nanotube addition. Journal of Materials $\quad$ Science, 49(8): 3225-3233. https://doi.org/10.1007/s10853-014-8027-4

[11] Li, Y., Chen, C., Xu, J., Zhang, Z., Yuan, B., Huang, X. (2015). Improved mechanical properties of carbon nanotubes-coated flax fiber reinforced composites. Journal of Materials Science, 50(3): 1117-1128. https://doi.org/10.1007/s10853-014-8668-3

[12] Najafi, G. (2018). Diesel engine combustion characteristics using nano-particles in biodiesel-diesel blends. $\quad$ Fuel, 212: 668-678 https://doi.org/10.1016/j.fuel.2017.10.001

[13] Basha, J.S. (2018). Impact of Carbon Nanotubes and DiEthyl Ether as additives with biodiesel emulsion fuels in a diesel engine-An experimental investigation. Journal of the Energy Institute, 91(2): 289-303. https://doi.org/10.1016/j.joei.2016.11.006

[14] Tewari, P., Doijode, E., Banapurmath, N., Yaliwal, V. (2013). Experimental investigations on a diesel engine fuelled with multiwalled carbon nanotubes blended biodiesel fuels. International Journal of Emerging Technology and Advanced Engineering, 3(3): 72-76.

[15] Basha, J.S. (2015). Preparation of water-biodiesel emulsion fuels with CNT \& Alumina nano-additives and their impact on the diesel engine operation. SAE Technical Paper, SAE 2015 World Congress \& Exhibition.

[16] Basha, J.S., Anand, R. (2014). Performance, emission and combustion characteristics of a diesel engine using Carbon Nanotubes blended Jatropha Methyl Ester Emulsions. Alexandria Engineering Journal, 53(2): 259273.

[17] Moy, D., Niu, C., Tennent, H., Hoch, R. (2002). Carbon nanotubes in fuels. Patent No.: US 6,419,717 B2

[18] Alias, A., Thegaraju, D., Sharma, K. (2013). Effect of carbon nanotube dispersions to the palm oil dieselbiodiesel blend properties. International Conference on Mechanical Engineering Research (ICMER2013).

[19] Faizal, H.M., Shamsuddin, H.S., Harif, M.H.M., Hanaffi, M.F.M.A., Rahman, M.R.A., Rahman, M.M., Latiff, Z. (2018). Torrefaction of densified mesocarp fibre and palm kernel shell. Renewable Energy, 122: 419-428. https://doi.org/10.1016/j.renene.2018.01.118

[20] Bhattacharya, S., Leon, M.A., Rahman, M.M. (2002). A study on improved biomass briquetting. Energy for Sustainable Development, 6(2): 67-71.

[21] Husain, Z., Zaina, Z., Abdullah, Z. (2002). Briquetting of palm fibre and shell from the processing of palm nuts to palm oil. Biomass and Bioenergy, 22(6): 505-509. https://doi.org/10.1016/S0961-9534(02)00022-3

[22] Faizal, H., Latiff, Z., Wahid, M.A., Darus, A. (2010). Physical and combustion characteristics of biomass residues from palm oil mills. New Aspects of Fluid Mechanics, Heat Transfer and Environment, 34-38.

[23] Mohd Faizal, H., Shamsuddin, H.S., Heiree, M.H.M., Muhammad Ariff Hanaffi, M.F., Abdul Rahman, M.R., Rahman, M.M., Latiff, Z.A. (2018). Torrefaction of densified mesocarp fibre and palm kernel shell. Renewable Energy, 122: 419-428. https://doi.org/10.1016/j.renene.2018.01.118

[24] Rabier, F., Temmerman, M., Böhm, T., Hartmann, H., Jensen, P.D., Rathbauer, J., Carrasco, J., Fernández, M. (2006). Particle density determination of pellets and briquettes. Biomass and Bioenergy, 30(11): 954-963. https://doi.org/10.1016/j.biombioe.2006.06.006

[25] Al-Widyan, M., Al-Jalil, H., Abu-Zreig, M., AbuHamdeh, N. (2002). Physical durability and stability of olive cake briquettes. Canadian Biosystems Engineering, 44: 3.41-3.46

[26] Chin, Y.S., Aris, M.S. (2012). A Study of Biomass Fuel Briquettes from Oil Palm Mill Residues. In: ESTCONICPER 2012, KL Convention Centre.

[27] Cai, J., He, Y., Yu, X., Banks, S.W., Yang, Y., Zhang, X., Yu, Y., Liu, R., Bridgwater, A.V. (2017). Review of physicochemical properties and analytical characterization of lignocellulosic biomass. Renewable and Sustainable Energy Reviews, 76: 309-322. https://doi.org/10.1016/j.rser.2017.03.072

[28] Nyakuma, B.B., Ahmad, A., Johari, A., Tuan, T.A., Oladokun, O., Aminu, D.Y. (2015). Non-Isothermal Kinetic Analysis of Oil Palm Empty Fruit Bunch Pellets by Thermogravimetric Analysis. Chemical Engineering Transactions, 45 https://doi.org/10.3303/CET1545222

[29] Kim, S.W., Chung, W.S., Sohn, K.S., Son, C.Y., Lee, S. (2009). Improvement of flexure strength and fracture toughness in alumina matrix composites reinforced with 
carbon nanotubes. Materials Science and Engineering: A, 517(1-2): 293-299. https://doi.org/10.1016/j.msea.2009.04.035

[30] Uemura, Y., Omar, W.N., Tsutsui, T., Yusup, S.B. (2011). Torrefaction of oil palm wastes. Fuel, 90(8): 2585-2591. https://doi.org/10.1016/j.fuel.2011.03.021

[31] Nyakuma, B.B., Johari, A., Ahmad, A., Abdullah, T.A.T. (2014). Comparative analysis of the calorific fuel properties of empty fruit bunch fiber and briquette. Energy Procedia, 52: 466-473. https://doi.org/10.1016/j.egypro.2014.07.099

[32] Loh, S.K. (2017). The potential of the Malaysian oil palm biomass as a renewable energy source. Energy Conversion and Management, 141: 285-298. https://doi.org/10.1016/j.enconman.2016.08.081

[33] Nyakuma, B.B., Ahmad, A., Johari, A., Abdullah, T.A., Oladokun, O., Alkali, H. (2017). Fluidised bed gasification and chemical exergy analysis of pelletised oil palm empty fruit bunches. Chemical Engineering Transactions, 56(1): 1159-1164.

[34] Faizal, H.M., Latiff, Z., Iskandar, M.A.M. (2015). Characteristics of binderless palm biomass briquettes with various particle sizes. Jurnal Teknologi, 77(8).

[35] Ivanova, T., Mendoza Hernández, A., Bradna, J., Fernández Cusimamani, E., García Montoya, J., Armas Espinel, D. (2018). Assessment of Guava (Psidium
Guajava L.) Wood Biomass for Briquettes' Production. Forests, 9(10): 613. http://dx.doi.org/10.3390/f9100613

[36] Slopiecka, K., Bartocci, P., Fantozzi, F. (2012). Thermogravimetric analysis and kinetic study of poplar wood pyrolysis. Applied Energy, 97: 491-497. https://doi.org/10.1016/j.apenergy.2011.12.056

[37] Damartzis, T., Vamvuka, D., Sfakiotakis, S., Zabaniotou, A. (2011). Thermal degradation studies and kinetic modeling of cardoon (Cynara cardunculus) pyrolysis using thermogravimetric analysis (TGA). Bioresource Technology, 102(10): 6230-6238. https://doi.org/10.1016/j.biortech.2011.02.060

[38] Nemanova, V., Abedini, A., Liliedahl, T., Engvall, K. (2014). Co-gasification of petroleum coke and biomass. Fuel, 117: 870-875. https://doi.org/10.1016/j.fuel.2013.09.050

[39] Nyakuma, B., Oladokun, O., Bello, A. (2018). Combustion kinetics of petroleum coke by isoconversional modelling. Chemistry \& Chemical Technology, 12(4): 505-510. http://dx.doi.org/10.23939/chcht12.04.505

[40] Açıkalın, K. (2011). Pyrolytic characteristics and kinetics of pistachio shell by thermogravimetric analysis. Journal of Thermal Analysis and Calorimetry, 109(1): 227-235. https://doi.org/10.1007/s10973-011-1714-3 